\title{
Research on Financial Internal Control Optimization of Accounting Firms Based on Information Management Technology
}

\author{
Liu Ping ${ }^{1, a}$, Wang Wenbo ${ }^{1, b}$ \\ ${ }^{1}$ School of Finance and Public Administration, Harbin University of Commerce \\ No.1 Xuehai Street, Songbei District, Harbin city, Heilongjiang Province
}

\begin{abstract}
With the advent of the information age, the information management technology of all walks of life is improving day by day, and Chinese economic development has entered a brand new mode. Therefore, enterprises also need to keep pace with the times and carry out appropriate changes and reforms in their internal control management. As intermediary organizations connecting the government and enterprises, accounting firms are the bridges between the owners and operators of enterprises. Therefore, they have strong independence and objectivity. However, due to the short rise of accounting firms in China, the research on accounting firms in China is limited, and the scale is mainly small and medium-sized. As a monitoring method, internal control can effectively avoid the risks existing in the development process of small and medium-sized accounting firms in China, and effectively supervise the working ability and moral level of their auditors. Therefore, under the perspective of informational environment, this paper makes a brief analysis of the problems and causes existing in the establishment of the internal control system of accounting firms in China based on the study of the relationship between financial internal control and accounting firms. Meanwhile, a series of solutions to these problems have been developed in order to provide some effective reference basis for future research and promote the transformation and reform of the financial internal control of accounting firms in China.
\end{abstract}

\section{Introduction}

Since 1981, Chinese CPA system has been gradually restored, and the first accounting firm was established in Shanghai. With the development in the next few years, Chinese accounting industry has experienced four different stages: restoration and reconstruction, normative development, system innovation, and comprehensive reform. In different stages of development, our accounting industry has experienced a development process from scratch, the perfection of relevant systems and the perfection of laws and regulations system, so that Chinese accounting industry has gradually embarked on the road of legal management. With the continuous innovation of the accounting system, Chinese accounting industry has broken the bottleneck of development and gradually eliminated its own disadvantages within the industry. Under the leadership of the government, the existing system has also been continuously optimized and reformed. In the process of reform, the responsibility and power relationship of the accounting industry has also changed greatly. Certified public accountants can gradually break away from the original responsibility and power constraints. In the work, specific problems can be analyzed from a more objective and independent perspective, so that certified public accountants can have greater freedom and autonomy in their work. In recent years, from the perspective of the development and research of the accounting industry at home and abroad, accounting firms mainly take going out as a specific symbol to promote the rapid development of accounting firms as far as possible.

\section{Current Situation and Existing Problems of Financial Internal Control of Accounting Firms Under Information Environment}

\section{A. Current Situation of Financial Internal Control of Accounting Firms Under Information Environment}

On the whole, China's accounting firms are in the initial stage of development. The lack of development time and the ability and experience in dealing with business seriously restrict the development of accounting firms in China. In terms of environmental control, many accounting firms suffer from unclear strategic objectives and poor ability to undertake business independently. The construction of the organization seems reasonable, but the problems of serious formalism and excessive concentration of power have become the root of hindering the development of Chinese accounting firms.

From the perspective of risk assessment, Chinese accounting firms pay more attention to the assessment of business risks, and lack the ability to estimate and assess customer risks, which leads to many unnecessary disputes caused by customer risks ${ }^{[1]}$. In terms of control 
activities, the implementation of the business is slow, the review at the end of the business is relatively random, and the collection and transmission of information lack real-time effect. All these are the real reflection of the current situation of Chinese accounting firms. It is mainly due to the insufficient attention paid to the supervision of accounting firms in China and the lack of effective supervision and management system to supervise the daily work of accounting firms. This is also an urgent problem to be solved in the process of strengthening the internal control of Chinese accounting firms at present.

\section{B. Existing Problems of Financial Internal Control of Accounting Firms Under Information Environment}

1) Internal Control Decisions of Accounting Firms Are Not Clear

At present, the common establishment system of small and medium-sized accounting firms is partnership. The establishment cost is low and there is no miscellaneous establishment procedure. Only two or three certified public accountants and certain start-up capital are needed to register and establish an accounting firm. This kind of small and medium-sized accounting firms generally take simple audit business as the main work category, and do not have a more detailed and complete internal control system ${ }^{[2]}$. As the development mode of accounting firms is constantly updated, such a simple internal control system governing small and medium-sized accounting firms can no longer meet the needs of development. If the financial internal control system is not updated, the accounting firm will not be rigorous in the decision-making process, and the specific measures cannot be implemented accurately and effectively. This may lead to the doubts and differences of partners on the internal control system, which is not conducive to the internal control management of accounting firms.

\section{2) The Risk Management System Is Not Yet Sound}

Compared with the internal control of western accounting firms, the risk management system of Chinese generally small and medium-sized accounting firms has not been perfect, which is generally reflected in the lack of risk assessment system. It is a major criticism of the development of accounting firms that some risks and loopholes in the process of internal control management cannot be discovered, reflected and solved in a timely manner. In the aspect of risk identification, the effective identification of inherent risk and possible audit risk is an issue that the internal control of accounting firms should pay great attention to. In terms of risk measurement system, the current domestic mainstream methods of risk measurement include standard method, index method, loss distribution method, internal measurement method, etc. These more dominant and focused risk measurement methods have not been fully implemented and reflected in the internal control management of small and medium-sized accounting firms in China. In terms of risk control system, with the development of economy, audit process needs to be more rigorous. But from an objective point of view, not all risks can be controlled and avoided. If there is not a set of effective risk control system in the accounting firm to protect the stability of the accounting firm's internal control to the greatest extent when risks appear, it will bring uncertainty to the long-term development of the accounting firm in the future.

\section{3) The Internal Control Process Is Quite Different}

Today's small and medium-sized accounting firms have not formed a unified internal control system. Generally speaking, small and medium-sized accounting firms develop internal control system based on their own business characteristics and actual needs to, which lack of scientific and rational to a certain extent. In view of the current accounting environment, audit objects are more dispersed, which will have stricter requirements on accounting firms. For the internal control management, its quality of practice has become a very important issue. Small and medium-sized accounting firms in China may suffer from lack of contract management system, lack of high-quality talents and insufficient follow-up training, leading to the lack of professional competence of small and medium-sized accounting firms, which is not conducive to the optimization of their own internal control management system.

\section{Analysis On the Causes of Problems Existing in Financial Internal Control of Accounting Firms Under Information Environment}

\section{A. Accounting Firms Have a Loose Internal Control Environment}

Generally, the loose internal control environment of an accounting firm may be reflected in the unclear responsibilities of each post and the long-term solidification of management personnel. This limits the effectiveness of the accounting firm internal control system to a certain extent, so that when the accounting firm internal risk appears, the relevant personnel who assess the remediation risk can not accurately and effectively come up with the corresponding solution, thus lagging behind the effective process of internal control ${ }^{[3]}$. At the same time, the unclear responsibilities of each post and the unreasonable division of labor will directly affect the work efficiency of the accounting firm. In the interconnected working environment of accounting firms, the occurrence of this phenomenon will affect the final audit results, thus affecting the benign development of accounting firms to a large extent.

\section{B. The Risk Awareness of Internal Control Personnel in Accounting Firms is Weak}

The weakness of risk awareness of internal control personnel in accounting firms is generally reflected in the backward risk assessment methods and the insufficient professional competence of risk control personnel. In general, the accounting firms' approach to risk assessment has not changed over the years. With the development of economy and the change of times, backward risk assessment method is no longer enough to support the benign and long-term development of accounting firms, and its limitations are becoming more 
and more obvious. At the same time, the low ability of internal control personnel in accounting firms to find and deal with risk issues in a timely manner is a very serious problem for them. The low ability of personnel to deal with risk and the delay in finding problems will lead to the accumulation of risk problems. When the problems really threaten the development of accounting firms, it will be too late.

\section{Users of Financial Statements Are More Dependent on Accounting Firms}

From the perspective of the current accounting environment, the users of financial statements are more dependent on accounting firms, and the number and scale of accounting firms have increased to different degrees. With the development of economy, the increasing dependence of financial statement users on accounting firms will lead to the weakening of their own abilities. When the internal control management of an accounting firm cannot provide specific measures, it will directly affect the integrity and effectiveness of the preparation of financial statements, which is not conducive to the benign and long-term development of an accounting firm.

\section{$4 \quad$ The Strategy of Financial Internal Control Optimization in Accounting Firm Under Information Environment}

\section{A. Optimizing the Financial Internal Control And Management Environment of Accounting Firms}

\footnotetext{
1) Optimizing the Organizational Structure of Accounting Firms

The organizational structure is the framework of the accounting firm's various businesses. The optimization and adjustment of the organizational structure is conducive to improving the fluency of the accounting firm's various works. In terms of the actual work situation, it is mainly to optimize and adjust the policies and systems related to human resources ${ }^{[4]}$. The appointment and selection of talents must have a relatively scientific method and standard. In addition to ensuring the competence of auditors, their ethical and professional qualities should also be examined. In this way, we can ensure that auditors can strictly require themselves in accordance with relevant standards of audit staff in their future work and provide objective and accurate audit reports for enterprises, thus ensuring the stability of internal control personnel of accounting firms.
}

\section{B. Establishing And Improving Financial Internal Control Supervision System of Accounting Firms}

1) Building an Effective Risk Assessment Mechanism

Audit work is one of the main businesses of accounting firms. The core idea of audit work is to keep a skeptical attitude and avoid possible risks as much as possible. Therefore, in the daily training, auditors should also take this as the core idea of training. From the perspective of risk management, accounting firms must infiltrate the awareness of risk prevention into the management work and enhance the importance of risk management ${ }^{[5]}$. At the same time, an effective risk assessment mechanism should be established. In the actual work, customers can be classified according to different types and their choices, so as to effectively avoid the risks that may exist in the business development process. Only strict checks on customers can reduce the possibility of risks to the lowest, so as to improve the internal control mechanism.

\section{Improving the Internal Work Efficiency of Accounting Firms}

\section{1) Building Financial Information Platform And} Further Improving Work Efficiency

In the study of the internal control optimization of accounting firms, although we emphasize that we should not pay too much attention to the quality of audit, it does not mean that we can ignore the importance of audit quality to accounting firms. Audit work is one of the major businesses of accounting firms. With the advent of the information age, audit work has been changing from traditional audit to modern audit ${ }^{[18]}$. Therefore, in terms of business, accounting firms also need to keep pace with the times, gradually connect with the information age by building financial information platform, and effectively improve their work efficiency through the application of modern equipment and software.

2) Establishing Electronic Financial Files Management System

In the work of accounting, it is a common and unavoidable situation that the work cannot be completed on time due to heavy tasks. In the information age, the transmission of electronic data plays an increasingly indispensable role. In order to make the work of accounting firms more convenient and efficient, electronic data is essential ${ }^{[6]}$. In the future, the paper data such as accounting vouchers, accounting archives and financial statements can be managed electronically. Meanwhile, parallel electronic file classification can be carried out in the financial department of an accounting firm, so that the required data can be found more conveniently and quickly in the year-end audit. In the process of electronic file management, it is necessary to pay attention to the integrity of data. This requires its electronic data to be archived in a unified time to avoid risks. It can be shown in Figure 1 for the corresponding process about how to conduct electronic file management for accounting firm's financial internal control. 


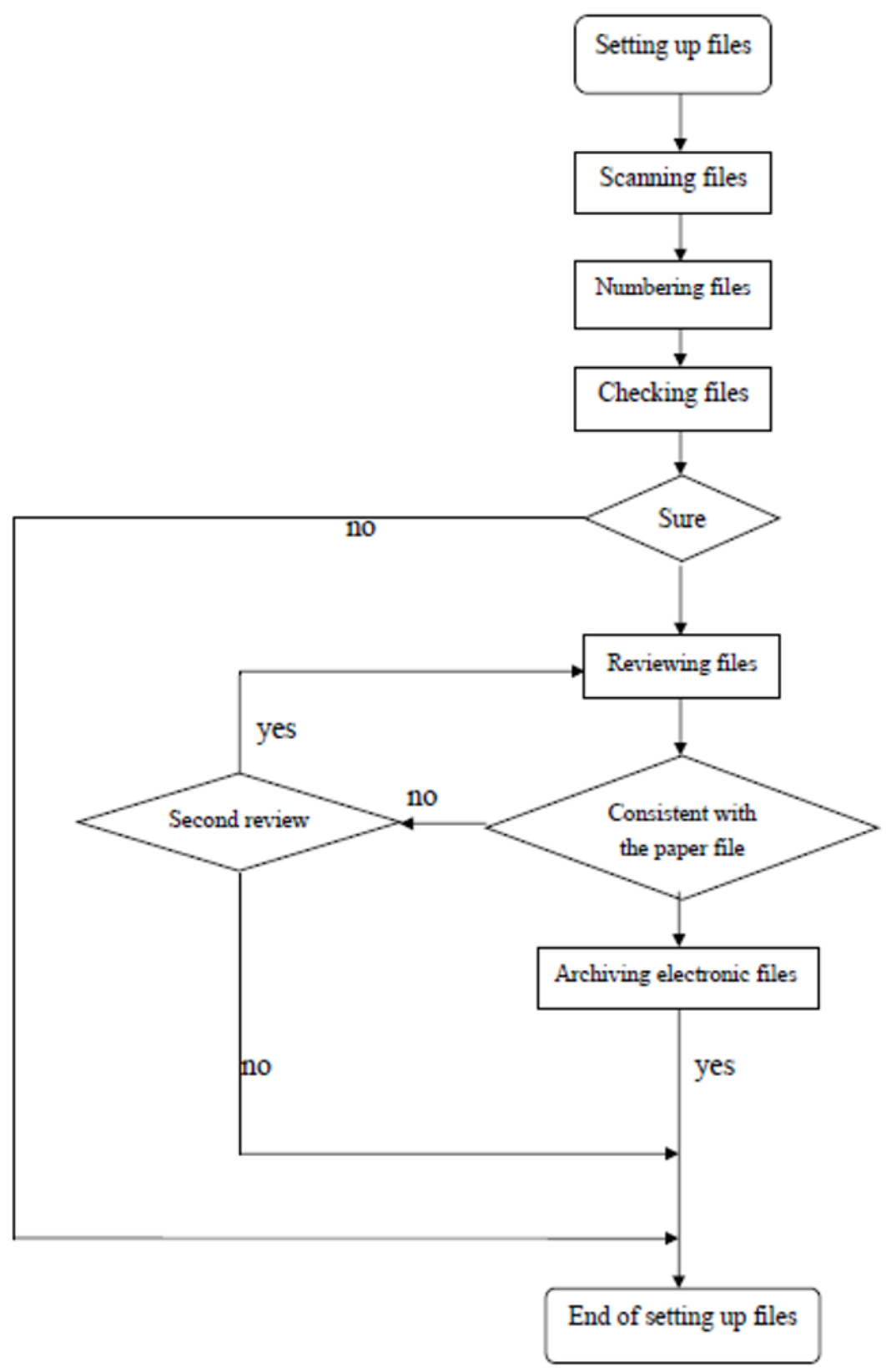

Figure1 Flow chart of electronic financial files filing business

\section{Conclusion}

Through the analysis and elaboration of the current situation of financial internal control of Chinese accounting firms, this paper clarifies the problems existing in the operation and development process of Chinese accounting firms, and clarifies the relationship between the financial internal control and the development of accounting firms. Based on the above analysis, the optimization conclusions of several accounting firms can be given according to personal suggestions:

First of all, the important characteristic of the information age is the rapid change of information. Therefore, in the process of optimizing its internal control, we must adopt the policy of keeping pace with the times, so that it can meet the actual needs of its development. In this way, we can make sure that the decisions made by the decision-making level have practical significance and avoid some risks.

Secondly, in terms of the actual situation in China, the development time of accounting firms is relatively short, and the scale of accounting firms in the market is mainly small and medium-sized. Therefore, in the process of optimizing its internal control, we must start from the aspect of risk avoidance, with risk reduction as the priority and profit as the second.

Thirdly, auditors are the key personnel for accounting firms to perform their functions. In the process of optimizing internal financial control, auditors must pay attention to the monitoring of their own ability and moral level. Competent and ethical audit staff are the foundation for the future development of accounting firms and must be valued. 
Finally, for relevant personnel of financial internal control of the accounting firms, they should improve the professional quality and ability. At the same time they should strengthen their moral education quality, so as to improve the financial internal quality of practice of accounting firms.

\section{Reference}

1. Park S J, Oh M J, Lee E C. The Effect of Personnel Characteristics in the Internal Accounting Control System on Discretionary Tax Accruals: Evidence from Korea $[\mathrm{J}]$. Australian Accounting Review, 2018 (1).

2. Curtis M B, Taylor E Z. Developmental mentoring, affective organizational commi tment, and knowledge sharing in public accounting firms[J].
Journal of Knowledge Management, 2017, 22 (1) :00-00

3. Duff A.Intellectual capital disclosure: evidence from UK accounting firms[J] . Journal of Intellectual Capital, 2018, 19( 1):JIC-06-2017-0079.

4. Luo Jinhua, Analysis on Accelerating the Construction of Internal Control of Accounting Firms, China Township Enterprises Accounting, February 15, 2018:16-18

5. Pu Lianji, On the Construction of Internal Control System and Practice of Modern Marketing in Accounting Firms (the next issue), September 21-13-15, 2018

6. Li Jun, Exploration on Internal Control System Constr uction and Practice of Accounting Firms, Modern Economic Information, 2018-07-25:11-14 